\section{The role of associative organization in free recall under five different presentation conditions*}

\author{
RUSSELL A. FOOTE and HOWARD R. POLLIO \\ The University of Tennessee, Knoxville, Tenn. 37916
}

The present experiment investigated the effects of a number of different presentation conditions on the recall of lists differing in interitem associative strength (IIAS). Results showed the usual superiority of a highly organized list over a list having no such organization under discrete presentation conditions, but no difference in recall when $S$ s were allowed to deal with all items simultaneously and impose their own organization. This finding was interpreted to mean that typical discrete-item presentation conditions permit Ss to use only the most obvious organizational principles in accomplishing recall-roughly those defined by IIAS-whereas under conditions when such restrictions are removed $S$ s are free to develop idiosyncratically meaningful structures and consequently show minimal differences in recall due to differences in IIAS.

A number of studies have shown that when lists of verbal material are presented one item at a time to Ss for subsequent recall, the associative structure of these lists is highly predictive of the number of items recalled (Deese, 1959; Rothkopf \& Coke, 1961; Weingartner, 1964). In all of these investigations, such presentation insured equal exposure time for each item and precluded consideration of all items at once. Under these conditions, associative factors strongly affect recall, with the interitem associative strength (IIAS) of a set of words being positively related to the number of items recalled.

It seems likely, however, that discrete item presentation effectively prevents each $S$ from organizing stimulus items into an individually relevant organization capable of facilitating recall. Under these constrained circumstances, $\mathrm{S}$ is forced to depend upon the most obvious-but not necessarily the most idiosyncratically useful-organization implied by the stimulus words themselves. Removing these restrictions should allow each $S$ to organize stimulus words into a subjectively useful organization and thereby minimize the role of IIAS in recall. On this basis, it seems reasonable to expect that when $S$ is allowed to attend to all list items simultaneously, differences in IIAS will have little or no differential effect on the number of items appearing in recall.

$$
\text { SUBJECTS }
$$

All 121 Ss were undergraduate students enrolled in introductory psychology courses at The University of Tennessee. Both sexes were about equally represented and all Ss were volunteers.

\section{STIMULUS MATERIALS}

Two lists of 22 words each were used, with the lists designated "butterfly" and

* This research supported in part by Grant MH80903 from the U.S. Public Health Service. "random." Words in the butterfly list were 21 frequent word associations to the stimulus word BUTTERFLY and the stimulus word itself. Words in the random list were chosen such that no word in the list evoked any other as a primary associate on the basis of association norms. The total number of interitem associative connections is 93 for the butterfly list and 0 for the random list (see Pollio, 1963, for a discussion of the procedure used to obtain these values). The words from each list were presented to $S s$ in all conditions of the experiment typed in capital letters on $3 \times 5$ in. white vinyl cards often used in the operation of a Hunter Cardmaster (Model 340). The specific words used in this study are presented in Table 1.

\section{PROCEDURE}

For each word list, five basic stimulus presentation conditions were used, with 11 Ss in each condition. An additional condition-also employing 11 Ss-was used only with the random list.

In Condition 1, each S was seated at a table in the experimental room and presented with a set of 22 word cards comprising one of the two word lists. The word cards were placed before $S$ in a stack, in a different random order for each $S$. Each $S$ was advised to sort words into groups on any basis he might think appropriate. The only restriction was that all words remain exposed to $S$ at all times. No time limit for sorting was imposed, and $\mathrm{S}$ was not told that he would be asked for a subsequent recall of the words. When $S$ indicated he had completed his sorting, he was asked to move to another table with his back to the word cards and recall as many of the words as possible by speaking them into the microphone of a tape recorder. No restrictions were placed on order of recall. Postrecall questioning indicated that no $S$ anticipated the recall task. In this and all subsequent conditions of the present experiment, Ss were allowed 2 min for oral recall.

Under Condition 1, Ss were asked to impose their own structure on the stimuli presented and to proceed at their own rates in organizing this material. In view of the different IIAS values for the two lists, a difference in mean sorting time was expected between the lists. The actual values obtained were $3.51 \mathrm{~min}$ for the butterfly list and $4.50 \mathrm{~min}$ for the random list. To establish uniformity of prerecall exposure time across the various stimulus presentation conditions, all $\mathrm{Ss}$ in Conditions 2 through 5 were yoked for stimulus exposure time to an appropriate word-list counterpart in Condition 1 .

Ss in Condition 2 were treated the same as those in Condition 1 except that they were advised to expect a free-recall task immediately after sorting. Each $\mathrm{S}$ was also told the amount of time he had for sorting as determined by his yoked counterpart and to study the words until $\mathrm{E}$ told him to stop in the event that he had completed his grouping before sorting time expired. All Ss did, in fact, complete their sorting before time ran out.

In Condition 3, all 22 words were presented simultaneously in a block display of the word cards on a table top in the experimental room. The display was arranged in a configuration of three rows of six words each and one row of four words, with the four words composing the bottom row. A different random order of display was presented to each $\mathrm{S}$. When $\mathrm{S}$ entered the experimental room, he was

Table 1

Stimulus Words Contained in the Butterfly and Random Lists

\begin{tabular}{llll}
\hline & \multicolumn{3}{c}{ Word Set } \\
\hline YELLOW & Butterfly & & Random \\
BEE & SPRING & SWORD & ART \\
BLLE & COLOR & PLAIN & STARS \\
BLG & DOG & DANGER & DAWN \\
BIRD & FLOWER & WISE & TABLE \\
WING & SKY & FLOWER & BOAT \\
WASP & PRETTY & BITTER & SILK \\
WARM & FLLTTER & MONEY & FAITH \\
BUTTERFLY & MOTH & TRLTH & NLRSE \\
COCOON & FLY & GLOW & WAGON \\
SUMMER & LIGHT & JOY & CITY \\
\hline
\end{tabular}


Table 2

Means and Standard Deviations of Recall Variables as a Function of Stimulus List and Stimulus Presentation Condition

\begin{tabular}{|c|c|c|c|c|c|c|c|c|}
\hline \multirow{3}{*}{$\begin{array}{l}\text { Stimulus List and Stimulus } \\
\text { Presentation Condition }\end{array}$} & \multicolumn{8}{|c|}{ Number Recalled } \\
\hline & \multicolumn{2}{|c|}{ Tokens } & \multicolumn{2}{|c|}{ Repeats } & \multicolumn{2}{|c|}{ Intrusions } & \multicolumn{2}{|c|}{ Types } \\
\hline & $\mathrm{M}$ & $\mathrm{SD}$ & $\mathbf{M}$ & $\mathrm{SD}$ & $\mathbf{M}$ & $\mathrm{SD}$ & $\mathbf{M}$ & SD \\
\hline \multicolumn{9}{|l|}{ Random } \\
\hline As sorting task only & 19.2 & 3.3 & 2.6 & 2.2 & 0.4 & 0.4 & 16.2 & 2.3 \\
\hline As sorting announced recall task & 19.5 & 2.5 & 1.3 & 1.3 & 0.1 & 0.9 & 18.1 & 2.1 \\
\hline In random simultaneous display & 19.7 & 5.4 & 3.3 & 3.2 & 0.2 & 0.4 & 16.3 & 3.1 \\
\hline In organized simultaneous display & 19.5 & 3.8 & 1.2 & 1.9 & 0.2 & 0.6 & 18.1 & 2.4 \\
\hline Discrete & 16.9 & 4.2 & 2.6 & 2.6 & 0.5 & 0.7 & 13.8 & 2.5 \\
\hline $\begin{array}{l}\text { As sorting announced recall task } \\
\text { with same exposure time as } \\
\text { for Butterfly list }\end{array}$ & 18.0 & 2.5 & 0.4 & 0.2 & 0.2 & 0.2 & 17.4 & 2.2 \\
\hline \multicolumn{9}{|l|}{ Butterfly } \\
\hline As sorting task only & 19.1 & 2.7 & 2.5 & 1.9 & 0.3 & 0.5 & 16.3 & 1.8 \\
\hline As sorting announced recall task & 18.2 & 3.3 & 1.8 & 2.4 & 0.1 & 0.9 & 16.3 & 2.8 \\
\hline In random simultaneous display & 20.1 & 4.5 & 3.6 & 3.6 & 0.0 & 0.0 & 16.5 & 2.9 \\
\hline In organized simultaneous display & 20.2 & 2.3 & 2.0 & 1.6 & 0.0 & 0.0 & 18.2 & 2.3 \\
\hline Discrete & 20.1 & 3.9 & 3.2 & 4.1 & 0.1 & 0.3 & 16.8 & 2.6 \\
\hline
\end{tabular}

seated at the table upon which the word cards were concealed by a white cardboard covering. He was instructed that when the covering was removed he was to study and attempt to memorize the words for subsequent recall. The $S$ was advised that he had a time limit (as determined by his yoked counterpart in Condition 1) for such study and memorization. When this period was completed, $\mathrm{S}$ was asked to move to another table with his back to the word cards and recall as many of these words as possible.

Ss in Condition 4 were treated the same as those in Condition 3 except for the way in which word cards were displayed. Under this condition, words were arranged in three rows of six words each and one row of four words as in Condition 3, except that the words were ordered sequentially from left to right and from top to bottom to reflect common categories that emerged in the sorts of the random and butterfly lists by $\mathrm{Ss}$ in an earlier experiment (Pollio \& Foote, in press). Words from separate categories were always sequenced in juxtaposition in the block display of word cards, although the sequencing of words within categories and of the categories themselves were always in a different random order for each $S$.

In Condition 5 , the words were shown to $S$ one at a time in the window of a Hunter Cardmaster (Model 340) at a 2-1 rate. Both the 1- and 2-sec periods were used in defining total list exposure time for a given $\mathrm{S}$-with total exposure time being determined by S's yoked counterpart in Condition 1. Words were shown in a different random order for each $S$. Subsequent random presentations of the list were continued until the total required exposure time expired. Each $S$ in this condition was instructed to remember as many words as possible for subsequent recall and was told the amount of time that he would have to see the words. At the completion of this period, $S$ was asked to move to a different table and to recall as many words as possible.

For the purpose of making a direct comparison of recall across lists-precluded in the other conditions because of differences in mean exposure time across the two lists-a sixth condition was used with the random list. In Condition 6 , Ss were treated the same as Ss in Condition 2; that is, they were asked to sort words with the knowledge that they would be asked for a subsequent recall. However, these Ss were yoked for exposure time to counterparts exposed to the butterfly list. RESULTS

Table 2 presents the means and standard deviations by stimulus presentation condition and word list for all words recalled (tokens), for repeats, for intrusions, and for all words recalled excluding repeats and intrusions (types). As indicated in Table 2, intrusions and repeats appeared infrequently in Ss' recall records. All subsequent analyses, consequently, deal only with recall types, and presentation of descriptive data for tokens, repeats, and intrusions is made for purposes of completeness only.

As indicated in Table 2, recall of types from the highly interassociated butterfly list is about the same for each of the five stimulus presentation conditions. An analysis of variance revealed no significant difference in recall of types across conditions for the butterfly list, $F(4,50)=1.12$. A Dunnett $(1955)$ test was done using Condition 5, the discrete presentation method, as the control situation and these results proved to be nonsignificant for any conditions i ridive to the control $(\mathrm{p}<.25)$. Table 2 , however, shows that for the random set there is an appreciably smaller recall when stimuli were presented discretely as in Condition 5 than when items were presented in any of the other four presentation conditions. An analysis of variance done over these data did show a significant presentation condition effect, $F(4,50)=4.01, p<.01$. Dunnett's test was again applied, using Condition 5 as the control, and produced significant differences $(p<.01)$ for all four comparisons. Despite the fact that all presentation conditions differed significantly from the control condition, none differed significantly among themselves.

As has been stated above, Ss in Condition 6 were shown the random words, asked for a sort, and advised that they would be asked for subsequent recall. All $\mathrm{Ss}$ in this condition were yoked for exposure time to counterparts in Condition 2 of the butterfly list. Table 2 reveals that mean recall is slightly better for words in the random list than for those in the butterfly list, although not significantly so $[t(20)=1.01, p>.20]$. With exposure time equated, the list with no IIAS was recalled at least as well as the highly interassociated list if Ss were not constrained to a discrete item presentation condition.

Although exposure time in Condition 5 was longer for Ss in the random group than for those in the butterfly group, a $t$ test run between these groups showed significantly greater recall for the butterfly list relative to the random list, $t(20)=2.44, \quad p<.05$. Thus, under constrained conditions, the high IIAS list is better recalled even if it had been exposed for a shorter time period.

\section{DISCUSSION}

As Deese (1965) has noted, investigation of verbal learning and recall has been pervasively influenced by the classical laws of association; particularly the laws of contiguity and frequency. Not only the variables investigated but the very manner in which experimental material is presented has been determined by explicit or more often by implicit acceptance of the law of contiguity. Thus, the usual practice of exposing items one at a time stems from an interpretation of memory that assumes it to depend upon the establishment of contiguity-based linkages between independent items.

The findings of the present experiment are quite clear in verifying previous results in showing a significant difference in recall for materials differing markedly in associative organization. The results of the present study indicate just as clearly, however, that such differences in recall dissipate when each $S$ is allowed to 
consider the individual items more or less simultaneously and then divide his time among items as he sees fit. It seems reasonable to assume that when the me thod of stimulus presentation limits $S$ to organizing stimulus materials along associative dimensions-as in the discrete method of stimulus presentation-he is at a distinct disadvantage in encoding a set of items with little or no inherent associative relatedness. However, when $S$ is afforded an opportunity to consider material as a whole, where he may concentrate his attention unequally over the material, he is able to structure the material independent of the degree of its associative organization. Such an opportunity to organize is especially important when stimulus jtems are minimally interassociated.

\section{REFERENCES}

DEESE. J. Influence of inter-item associative strength upon immediate free recall. Psychological Reports, 1959, 5, 305-312.

DEESE, J. The stricture of associations in language and thought. Baltimore: The John Hopkins Press, 1965.

DLNNEIT, C. A multiple comparison procedure for comparing several treatments with a control. Journal of the American Statistical A ssociation, 1955, 50, 1096-1121.

POLLIO, H. A simple matrix analysis of associative stnucture. Journal of Verbal Learning \& Verbal Behavior, 1963. 2, 166-169.

POLLIO, H., \& FOOTE, R. Memory as a reconstructive process. British Journal of Psychology, in press.

ROTHKOPF, E., \& COKE, E. The prediction of free recall from word association measures. Journal of Experimental Psychology, 1961, $62,433-438$.

WEINGARTNER, $\mathrm{H}$. The free recall of sets of associatively related words. Journal of Verbal Learning \& Verbal Behavior, 1964, 3, 6-10.

\section{History-related effects upon human escape responding: Are induction or extinction processes involved?}

\author{
HAROLD WEINER \\ Laboratory of Human Behavior, SMR, NIMH \\ Saint Elizabeths Hospital, Washington, D.C. 20032
}

Adult humans given either an FR 40 or DRI 20-sec conditioning history were exposed to an extinction procedure and then conditioned under an escape schedule. Despite comparable cessation of responding during extinction, FR 40-history Ss produced high-rate escape responding, while DRL 20-sec-history Ss gave low-rate escape responding. Taken in conjunction with previous findings, these results suggest that response induction rather than differential extinction is responsible for the persistence of FR- and DRL-history effects upon escape responding.

Inter-S differences in response rates have been observed under escape schedules with humans (Weiner, 1963b, 1964). Such differences can be controlled experimentally by providing $S$ s with different histories of conditioning. Thus, Weiner (1969) showed that high-rate and

low-rate escape performances are produced by Ss with a history of responding under a fixed-ratio (FR) or a differentialreinforcement-of-low-rate (DRL) schedule, respectively.

A question remains as to whether these history-related escape performances were due to differential rates of extinction responding following FR or DRL or to response induction from $F R$ or $D R L$ to escape responding. The present experiment attempted to answer this question by exposing FR- or DRL-history $S$ s to an extinction procedure prior to conditioning under an escape schedule.

\section{SUBJECTS}

Male and female adult humans, ages $18-63$, served. They were paid $\$ 3$ per hour irrespective of their operant performances.

\section{PROCEDURE}

The apparatus, task, and instructions were the same as used previously (Weiner, 1969). Essentially, Ss worked on a button to obtain as many points and to lose as few points on a counter as possible. They were told nothing about the purpose of the experiment, the nature of the experimental contingencies, or at what rate to press the response button. A force of approximately $20 \mathrm{~g}$ through a distance of $1 \mathrm{~cm}$ was required for an effective button press.

Ss were trained initially (given a history) under either an FR 40 schedule, where 40 button presses added 100 points to the counter, or a DRL $20 \mathrm{sec}$ schedule, where 100 -point additions to the counter occurred only if the $S s$ paused at least $20 \mathrm{sec}$ between two successive responses. Under the DRL 20-sec schedule, interresponse times of less than $20 \mathrm{sec}$ postponed reinforcements for at least $20 \mathrm{sec}$.

After FR 40 or DRL 20-sec histories, all Ss . were exposed to an extinction procedure (where no reinforcements were delivered) followed by conditioning under a 10-sec escape (Es 10-sec) schedule. The Es 10-sec schedule provided a series of 20-sec "point-loss periods" (PLPs), during which 100 points were subtracted from the score on the counter at the rate of 5 points per second. The time between PLPs was $10 \mathrm{sec}$. A button press prior to a PLP had no effect. A button press once a PLP began terminated the PLP. Thus, Ss could not avoid (postpone) PLPs but they could escape (terminate) them. Beyond a mandatory 5-point loss per PLP, the number of points lost and the duration of a PLP depended upon the latency of the escape response (i.e., the time interval between the onset of a PLP and the escape response).

Ss received 101 h conditioning sessions under the FR 40, DRL 20-sec, extinction, and Es 10-sec contingencies. Each conditioning session began with a zero score. Therefore, either a zero or a plus score on the counter was possible under the FR 40 and DRL 20-sec schedules, only a zero score could occur under extinction, and only a minus score could occur under 